\title{
A study to find the utility of MRI in the evaluation of painful hip joints NVP V. ${ }^{1}$, Sudha K J. ${ }^{2 *}$, Lakshmi Vineela M. ${ }^{3}$, Chandra T J. 4 DOI: https://doi.org/10.17511/ijmrr.2020.i04.05 \\ 1 Vinay NVP, Associate Professor, Department of Radiodiagnosis, GSL Medical College, Rajahmundry, Andhra Pradesh, India. \\ 2* Jaya Sudha K, Associate Professor, Department of Radiodiagnosis, GSL Medical College, Rajahmundry, Andhra Pradesh, India. \\ 3 Meka Lakshmi Vineela, Resident, Department of Radiodiagnosis, GSL Medical College, Rajahmundry, Andhra Pradesh, India. \\ 4 Jaya Chandra T, Scientist in charge, Central Research laboratory, GSL Medical College, Rajahmundry, Andhra Pradesh, India.
}

Introduction: Magnetic resonance (MR) imaging is a valuable tool in the evaluation of hip disorders. With these, a study was conducted to assess the role of MRI in the early evaluation of painful hip joints. Materials and Methods: It was a cross-sectional study conducted in the department of Radiodiagnosis, GSL Medical College, Rajahmundry. The study protocol was approved by the Institutional Ethical Committee. Patients presenting with acute or chronic hip pain pathology of all age groups, both gender who referred for MRI were included in the study. Imaging has been done with 1.5 Tesla Philips Achieva machines using abdominal surface coils and spine coils. Results: Out of the 30 participants, avascular necrosis was diagnosed in $46.6 \%$ (14) participants, joint effusion in $10 \%$ (3) cases, osteoarthritis (OA) in 4 (13.3\%) cases, tuberculosis (TB) in 10\% (3), $6.6 \%$ (2) each was diagnosed to be Perthe's, developmental dysplasia of the hip (DDH) and metastasis, respectively. All the pathological findings were diagnosed using MRI also. Conclusion: MRI helps in the evaluation of the involvement of articular cartilage in the form of $\mathrm{T} 2 \mathrm{~W}$ hyperintensity. It also helps in the evaluation of soft tissue involvement along with the detection of bone marrow edema.

Keywords: Evaluation, Study, Report, Patient, Imaging

Corresponding Author

Jaya Sudha K, Associate Professor, Department of Radiodiagnosis, GSL Medical College, Rajahmundry, Andhra Pradesh, India.

Email: gslcentralresearchlab@gmail.com
How to Cite this Article To Browse

Vinay NVP, Sudha K J, Vineela LM, Chandra T J. A study to find the utility of MRI in the evaluation of painful hip joints. Int J Med Res Rev. 2020;8(4):315319.

\section{Available From}

https://ijmrr.medresearch.in/index.php/ijmrr/article/ view/1170

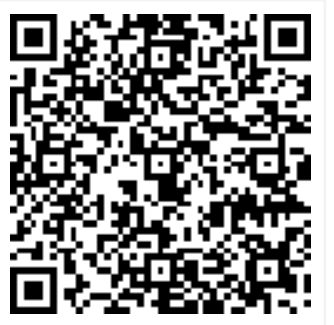

\section{Introduction}

The hip is a stable, major weight-bearing joint with significant mobility. Magnetic resonance (MR) imaging is a valuable tool in the evaluation of hip disorders because it enables assessment of articular structures, extra-
Articular soft tissues, and the osseous structures that can be affected by the hip disease [1]. In the setting of chronic hip pain, a normal-appearing radiograph, a nonspecific history, and clinical findings can be a difficult diagnostic dilemma.

The femoral head and neck and the intertro

$\begin{array}{cc}\begin{array}{c}\text { Manuscript Received } \\ 2020-03-17\end{array} & \begin{array}{c}\text { Review Round } \mathbf{1} \\ 2020-03-26\end{array} \\ \text { Conflict of Interest } & \text { Funding } \\ \text { No } & \text { Nil }\end{array}$

Review Round 2
2020-04-10
Ethical Approval
yes

() 2020 by Vinay NVP, Jaya Sudha K, Meka Lakshmi Vineela, Jaya Chandra T and Published by Siddharth Health Research and Social Welfare Society. This is an Open Access article licensed under a Creative Commons Attribution 4.0 International License https://creativecommons.org/licenses/by/4.0/ unported [CC BY 4.0].

\author{
Plagiarism X-checker \\ $5 \%$
}

Accepted 2020-08-25 Note 
-chanteric region are best appreciated on coronal MR images. Axial MR images provide good visualization of the articular space, hip musculature, and supporting ligaments [2]. MR imaging has been shown to be the most sensitive modality for imaging Avascular Necrosis (AVN). Screening of asymptomatic, high-risk patients may enable early intervention. The principal role of MR imaging is in establishing the diagnosis of AVN in symptomatic patients before radiographic changes become apparently visible.

MR imaging is becoming increasingly useful in the diagnosis and management of pediatric hip disorders. MR imaging offers several advantages that are especially important in the pediatric population. Because much of the pediatric hip is cartilaginous, it is often not optimally imaged with other modalities such as plain radiography, ultrasound (US) (after 6 months of age), and computed tomography (CT). MR imaging is unique in its ability to depict cartilage and is, therefore, especially efficacious in the evaluation of the pediatric hip [2].

It is believed that attention to the details of the MR examination technique and imaging protocol is essential for maximizing the diagnostic potential of MR imaging in the work-up of hip disease. Specific protocols that incorporate surface coil imaging, oblique image acquisition, and alternative pulse sequences are the foundation for successful hip studies. The use of GRE sequences is essential in the evaluation of cartilaginous disorders, particularly in pediatric hip disease [2]. With these, a study was conducted to assess the role of MRI in the early evaluation of painful hip joints

\section{Materials and Methods}

Settings: It was a cross-sectional study conducted in the department of Radiodiagnosis, GSL Medical College, Rajahmundry, Andhra Pradesh, India

Duration of study: The study was conducted from January 2015 to June 2016.

Sampling method: Random sampling was considered in this study.

Inclusion criteria: Patients presenting with acute or chronic hip pain pathology of all age groups, both gender who referred for MRI were included in the study.

Exclusion criteria: Patients with a history of acute
Trauma, claustrophobia, metallic implants insertion, cardiac pacemakers, and metallic foreign body in situ, who did not submit the informed consent were excluded from the study.

Sample size: All the individuals who satisfy the inclusion criteria during the study period were included in the study.

Imaging has been done with 1.5 Tesla Philips Achieva machine using abdominal surface coils and spine coils.

The following sequences were selected as per the requirement, TIW coronal - TE (18ms) TR (500 $700 \mathrm{~ms})$ slice thickness $(1-3 \mathrm{~mm}) ; \mathrm{T} 1 \mathrm{~W}$ axial - TE (18ms) TR (500 - 700ms) slice thickness (1 $3 \mathrm{~mm})$; T2W coronal - TE (100ms) TR (1000 - 1500 $\mathrm{ms})$ slice thickness $(1-3 \mathrm{~mm})$; T2W axial - TE $(100 \mathrm{~ms})$ TR $(1000$ - 1500ms) slice thickness (1 $3 \mathrm{~mm})$; STIR coronal - TE (30ms) TR (2700 $6000 \mathrm{~ms})$ slice thickness ( $3-5 \mathrm{~mm})$, PD sagittal TE (30ms) TR (2300 - 6500ms) slice thickness (3 $5 \mathrm{~mm})$; mFFE axial -T E (9.21ms) TR (500ms) slice thickness ( $1-3 \mathrm{~mm})$.

Statistical analysis: Statistical analysis was performed by using SPSS software version 21.0. statistics such as mean, percentages were used in this report.

\section{Results}

During the study period, a total of 30 participants were included; in this $56.7 \%$ (17) were male and $43.3 \%$ (13) were female participants, the malefemale ratio was 1.3 .

Age-wise, the study group was divided into 3 categories, 11 - 30 years, 31 - 50 years, and 51 70 years group.

Out of the 30 study participants, 19 (63.3\%) participants were included in 11 - 30 years group, 6 (20\%) participants were included in 31 - 50 years group and 5 (16.7\%) participants were included in 51 - 70 years group (Table 1 ).

Table-1: Age-wise distribution of the study participants.

\begin{tabular}{|l|l|l|}
\hline \multicolumn{1}{|c|}{ Age } & \multicolumn{1}{|c|}{ Number } & \multicolumn{1}{c|}{$\%$} \\
\hline $11-30$ & 19 & $63.3 \%$ \\
\hline $31-50$ & 6 & $20 \%$ \\
\hline $51-70$ & 5 & $16.7 \%$ \\
\hline Total & 30 & $100 \%$ \\
\hline
\end{tabular}


Table-2: Distribution of the study participants as per the pathology.

\begin{tabular}{|l|l|l|}
\hline \multicolumn{1}{|c|}{ Pathology } & \multicolumn{1}{c|}{ Number } & \multicolumn{1}{c|}{$\%$} \\
\hline AVN & 14 & 46.6 \\
\hline Joint Effusion & 3 & 10 \\
\hline OA & 4 & 13.3 \\
\hline TB & 3 & 10 \\
\hline Perthe's & 2 & 6.6 \\
\hline DDH & 2 & 6.6 \\
\hline Metastasis & 2 & 6.6 \\
\hline Total & 30 & 100 \\
\hline
\end{tabular}

Table 3: MRI findings among the OA participants $\mathbf{n}=4$.

\begin{tabular}{|l|l|l|}
\hline \multicolumn{1}{|c|}{ MRI Findings } & Number & $\%$ \\
\hline Articular cartilage T2W high signal & 4 & 100 \\
\hline $\begin{array}{l}\text { Indistinct trabeculae/signal loss in femoral head and neck on } \\
\text { T1W }\end{array}$ & 2 & 50 \\
\hline The indistinct zone between femoral head and acetabulum & 1 & 25 \\
\hline Subchondral signal loss & 2 & 50 \\
\hline Femoral head deformity & 1 & 25 \\
\hline
\end{tabular}

Out of the 30 participants, avascular necrosis (AVA) was diagnosed in $46.6 \%$ (14) participants, joint effusion in $10 \%$ (3) cases, osteoarthritis (OA) in 4 (13.3\%) cases, tuberculosis (TB) in $10 \%(3), 6.6 \%$ (2) each was diagnosed to be Perthe's, developmental dysplasia of the hip (DDH) and metastasis, respectively (Table 2). All the pathological findings were diagnosed using MRI also.

\section{Discussion}

MRI is a non-invasive, gold standard investigation in early diagnosis and evaluation of the extent of pathological involvement more accurately and also narrows the differential diagnosis [3,4]. The aim of this study was also at the early detection of the disease before the appearance of signs using MRI. This can help the clinician not only in the treatment patter and also prevent the further progression of the disease. This also can help the patient not only in the financial aspect but also can avoid the loss of working days, unnecessary usage of medication, and also prolonged hospital stay, and so on.

Out of 14 (100), AVA diagnosed participants, the MRI finding is as follows: $62.5 \%$ (10) showed bone marrow edema, double-line sign in $56.2 \%$ (9) cases, subchondral cyst in $8(50 \%)$ cases, femoral head altered contour in $2(12.5 \%)$ cases and femoral head fragment with collapse in $1(6.2 \%)$
Case. With this, the extent of the pathological involvement in already proven cases of AVN by MRI is $100 \%$. The present study findings were compared to the study done by Robinson $\mathrm{HJ}$ Jr et.al. [5]; in this study, the authors reported that 23 of the 96 hips that were suspected of having early-stage necrosis of the femoral head but showed slight or no radiographic changes were studied by repeat radiographs. Of the 23 hips, $18(78 \%)$ had positive changes on MRI; in the present study out of 14 hips, MRI detects 14 cases (100\%).

All the $3(100 \%)$ cases were positive for joint effusion on MRI, graded as mild, moderate, and severe at a rate of $33.3 \%$ (1) each, respectively in each grade. The amount of joint fluid was graded from 0 to 3 . The peak of bone marrow edema occurred in stage III disease $(72 \%)$ as per the study by Huang GS et al [6]. With an effusion, bone marrow edema was reported to be 12.6 times greater when the hip was painful than when it was not. Both bone marrow edema and joint effusions existed with a peak occurrence in stage III disease. Bone marrow edema seems to have a stronger association with pain than that of joint effusion in osteonecrosis of the femoral head [6]. In another study by Yang et al. reported that the main diagnostic MRI findings seen in transient synovitis were joint effusion, presence of synovial thickening, alterations in signal intensity of soft tissue, and bone marrow in the affected hip joint [7]. In this study, 10 patients were diagnosed as transient synovitis and the dominant MRI finding was joint effusion which was identified in all $(100 \%)$ patients, followed by synovial thickening was identified in $70 \%$ (7) patients, enhanced synovium in 50\% (5) patients and marrow edema in $20 \%$ (2) patients.

OA was reported to be the most common type of joint disease, is a heterogeneous group of conditions that result in common histopathologic and radiologic changes $[8,9]$. It is a slowly developing disorder that causes the biochemical breakdown of articular cartilage in the synovial joints, leads to non-uniform degeneration of articular cartilage and reparative formation of new bone, which results in stiffness and pain of the affected joint [10]. Out of $4(100 \%)$ OA pathology participants in this report, all the cases were detected on MRI, all showed T2W high signal. Indistinct trabeculae/signal loss in femoral head and neck on T1W was diagnosed and subchondral loss was diagnosed in $50 \%$ (2) each, respectively. The indistinct zone between femoral head and acetab- 
Ulum and femoral head deformity was detected in 1 $(50 \%)$ cases each respectively. In a study by Hayashi D et al. [11] the authors also reported similar findings.

All the three cases which were diagnosed to be TB were also confirmed by MRI also. Only synovial T2W hyperintensity and joint effusion in the form of high signal intensity within the joint space in $\mathrm{T} 2 \mathrm{~W}$ and STIR sequences were found in MRI.

It reveals the importance of MRI in the early detection of TB for strong clinical suspicion. Similar findings were reported by $\mathrm{Om} P$ et al. report [12]. Buxi et al. reported that MRI could detect $95 \%$ of hip TB cases and the 5\% gap may be due to the age of the participants because the investigators studied on pediatric age group [13].

The 2 cases which were pathologically reported to be Perthe' $s$ disease were also confirmed by MRI (100\%). Among these 1 (50\%) showed epiphyseal hyperintensity on T2W and the other one (50\%) showed bone marrow edema. And the 2 cases each of which were reported to be DDH and Metastasis were also confirmed by MRI.

On MRI $2(100 \%)$ cases shows along with the displacement of epiphyses, hyperintensity of the epiphyses on T2W, and bone marrow edema as hyperintensity on STIR sequence. MRI helps in the detection of the early stages of DDH and Perthe's by showing the involvement of epiphyses in the form of T2W hyperintensity before the actual displacement of epiphyses noted. It also helps in the evaluation of bone marrow edema.

It was reported by Luis S. Beltran et al., that crosssectional imaging techniques such as MRI proved to be affordable, improved techniques for the detection and characterization of DDH by providing morphologic information about acetabular deficiency [14].

Thus, MRI lies superiors in the evaluation of metastatic lesions by not only detecting the abnormal signal intensity lesions but also evaluates the cartilaginous and the extent of soft tissue involvement accurately, which helps in the appropriate treatment plan.

\section{Limitation}

Small sample size is the major limitation of the study.

\section{Conclusion}

MRI helps in the evaluation of the pain which is involved articular cartilage in the form of $\mathrm{T} 2 \mathrm{~W}$ hyperintensity.

\section{What does the study add to the existing knowledge?}

MRI surely helps in the evaluation of pain. It also helps in the evaluation of soft tissue involvement along with the detection of bone marrow edema.

\section{Author's contribution}

Dr. D Venkata Ramana Rao: Study design, data analysis, paper writing.

Dr. K Jaya Sudha: Study design, paper writing.

Dr. Meka Lakshmi Vineela: Main work, data analysis

Dr. T Jaya Chandra: Data analysis, paper writing, statistical part.

\section{Reference}

01. Manaster BJ. Adult Chronic Hip PainRadiographic Evaluation. Radiographics. 2000;20;S3-S25.

[Crossref]

02. Gabriel H, Fitzgerald SW, Myers MT, Donaldson JS, Andrew K, Poznanski. MR Imaging of Hip Disorders. Radiographics. 1994;14;763-781. [Crossref]

03. Shih TT, Su CT, Chiu LC, Erickson F, Hang YS, Huang KM. Evaluation of hip disorders by radiography, radionuclide scanning and magnetic resonance imaging. J Formos Med Assoc. 1993;92(8)737-744.

[Crossref]

04. Khanna AJ, Yoon TR, Mont MA, Hungerford DS, Bluemke DA. Femoral head osteonecrosis: detection and grading by using a rapid MR imaging protocol. Radiol. 2000;217(1)188-192. [Crossref]

05. Yang WJ, Im SA, Lim GY, Chun HJ, Jung NY, Sung MS, et al. MR imaging of transient synovitis- differentiation from septic arthritis. Pediatric Radiol. 2006;36(11)1154-1158. [Crossref] 
06. Huang GS, Chan WP, Chang YC, Chang CY, YuChen $C$, Joseph SV. MR imaging of bone marrow edema and joint effusion in patients with osteonecrosis of the femoral head- relationship to pain. AJR Am J Roentgenol. 2003;181(2)545549.

[Crossref]

07. Robinson Jr HJ, Hartleben PD, Lund G, Schreiman J. Evaluation of magnetic resonance imaging in the diagnosis of osteonecrosis of the femoral head, Accuracy compared with radiographs, core biopsy, and intraosseous pressure measurements. J Bone Joint Surg. $1989 ; 71(5) 650-663$.

[Crossref]

08. Mitchell DG, Rao V, Dalinka M, Spritzer CE, Gefter WB, Axel $L$, et al. MRI of joint fluid in the normal and ischemic hip. Am J Roentgenol. 1986;146(6)1215-1218.

[Crossref]

09. Boniatis I, Costaridou L, Cavouras D, Kalatzis I, Panagiotopoulos E, Panayiotakis G. A morphological index for assessing hip osteoarthritis severity from radiographic images. Brit J Radiol. 2008;81(962)129-136.

[Crossref]
10. Li KC, Higgs J, Aisen AM, Buckwalter KA, Martel W, McCune WJ. MRI in osteoarthritis of the hipgradations of severity. Magnetic Resonan Imag. $1988 ; 6(3) 229-236$.

[Crossref]

11. Xu L, Hayashi D, Roemer FW, Felson DT, Guermazi A. Magnetic resonance imaging of subchondral bone marrow lesions in association with osteoarthritis. Semin Arthritis Rheum. 2012;42(2)105-118.

[Crossref]

12. Shrestha OP, Sitoula P, Hosalkar HS, Banskota AK, Spiegel DA. Bone and joint tuberculosis, University of Pennsylvania. Orthopaed J. 2010;20;23-28.

[Crossref]

13. Buxi TB, Sud S, Vohra R. CT and MRI in the diagnosis of tuberculosis. Indian J Pediatr. 2002;69(11)965-972.

[Crossref]

14. Beltran LS, Rosenberg ZS, Mayo JD, De Tuesta MD, Martin O, Neto LP, et al. Imaging evaluation of developmental hip dysplasia in the young adult. Am J Roentgenol. 2013;200(5)10771088.

[Crossref] 